\title{
NOVAS TECNOLOGIAS, SUSTENTABILIDADE E MEIO AMBIENTE SADIO E EQUILIBRADO: UM DESAFIO PARA OS DIAS ATUAIS
}

Maria Cláudia da Silva Antunes de Souza

Doutora e Mestre em Derecho Ambiental y de la Sostenibilidad pela Universidade de Alicante - Espanha. Mestre em Ciência Jurídica pela Universidade do Vale do Itajaí - UNIVALI. Professora no Programa de Pós-Graduação Stricto Sensu em Ciência Jurídica, nos cursos de Doutorado e Mestrado em Ciência Jurídica, e na Graduação no Curso de Direito da Universidade do Vale do Itajaí - UNIVALI. Coordenadora do Grupo de Pesquisa "Estado, Direito Ambiental, Transnacionalidade e Sustentabilidade" cadastrado no CNPq/EDATS/UNIVALI. Coordenadora do Projeto de pesquisa aprovado no CNPq intitulado: "Análise comparada dos limites e das possibilidades da avaliação ambiental estratégica e sua efetivação com vistas a contribuir para uma melhor gestão ambiental da atividade portuária no Brasil e na Espanha". E-mail: mclaudia@univali.br

Kamilla Pavan

Doutoranda em Derecho Ambiental y de la Sostenibilidad pela Universidade de Alicante - Espanha. . Mestra do Programa de Pós Graduação Stricto Senso em Ciência Jurídica da Universidade do Vale do Itajaí - UNIVALI; linha de pesquisa Constitucionalismo e Produção do Direito. Mestra do Programa de Pós Graduação Stricto Senso em Derecho Ambiental y Sostenibilidad da Universidad de Alacant/Alicante/Espanha. Formação do Curso Preparatório da Magistratura do Estado do Rio Grande do Sul - AJURIS (2005). Especialista em Direito Previdenciário, pela Faculdade IMED (2009). Especialista em Direito Público, pelo Instituto Luiz Flávio Gomes (2011). Especialista Em Processo Civil, pela Universidade do Vale do Itajaí - UNIVALI. Bacharel em Direito pela Universidade de Passo Fundo/ RS (2004). Advogada regularmente inscrita da Ordem dos Advogados do Brasil, Subseção do Estado do Rio Grande do Sul. kamillapavan@hotmail.com

\section{Resumo}

O presente artigo científico tem por objeto a análise das novas tecnologias e da sustentabilidade no contexto social, econômico e ambiental como uma contribuição para preservaçáo ao meio ambiente. A sustentabilidade deve ser pensada numa perspectiva global, envolvendo todo o planeta, com equidade, fazendo que o bem de uma parte náo se faça à custa do prejuízo da outra. A Sustentabilidade, assim, passa a ser o conjunto de 
mecanismos necessários à manutenção de algo sem que gere danos (ou, pelo menos, os reduza) no ambiente referenciado, também levando em consideração os demais ambientes para que haja uma intenção de perfeito equilíbrio entre eles, não se privilegiando um em detrimento dos demais. Neste contexto objetivam-se entender suas dimensóes quanto às áreas que abrangem essa maneira de firmar um progresso com vista para o bem-estar da presente e futuras geraçóes. Como meio indutor do desenvolvimento sustentável, tem-se o estudo das novas tecnologias, como forma de adentrar concretamente no sistema do progresso sustentável. O seu objetivo científico é discutir a contribuição da sustentabilidade para amenizar as consequências do crescimento global frente e a extensa degradaçáo ambiental. Para desenvolver este estudo será por meio do esboço do princípio da sustentabilidade, como direção finalística de consideráveis meios de solução aos problemas desencadeados pela globalização, com tendência às inovaçóes, seja de natureza científica ou de natureza jurídica, sempre em direção da primazia do progresso humano sustentável. Quanto à Metodologia, foi utilizada a base lógica Indutiva por meio da pesquisa bibliográfica.

\section{Palavras-chave}

Sustentabilidade; Novas tecnologias; Meio Ambiente.

\section{Resumen}

Este trabajo de investigación tiene como meta al análisis de las nuevas tecnologías y la Sostenibilidad en el contexto social, económico y ambiental, como contribución a la preservación del medio ambiente. La sostenibilidad debe ser considerada desde una perspectiva global, involucrando a todo el planeta, con equidad, haciendo que el bien de una parte no hace que el costo de la pérdida de la otra. Por tanto, se convierte en la Sostenibilidad conjunto de mecanismos necesarios para el mantenimiento de algo sin que gestiona daños (o al menos reducirlos) en el entorno de referencia, teniendo también en cuenta las otras habitaciones por lo que hay una intención de equilibrio perfecto que, no favorecer una sobre la otra. En este contexto, el objetivo es entender sus dimensiones como a las áreas que cubren esta forma de progreso constante con miras al bienestar de las generaciones presentes y futuras. Inductor como un medio de desarrollo sostenible, ha sido el estudio de las nuevas tecnologías como una forma de introducir concretamente en el progreso sostenible del sistema. Su objetivo científico es discutir la contribución de la sostenibilidad para mitigar las consecuencias del crecimiento global en comparación y la extensa degradación del medio ambiente. Para desarrollar este estudio será a través del principio de contorno sostenibilidad, como la dirección intencional de considerable solución de los medios de comunicación a los problemas causados por la globalización, con tendencia a las innovaciones, ya sea la naturaleza científica o jurídica, siempre hacia la 
primacía del progreso humano sostenible. En cuanto a la metodología, se utilizó la lógica inductiva través de la búsqueda bibliográfica.

\section{Palabras clave}

Sostenibilidad; Nuevas Tecnologias; Medio Ambiente.

\section{Introdução}

Neste presente artigo procura-se contextualizar o paradigma da sustentabilidade como uma forma de contribuição para amenizar os impactos ambientais, econômicos e sociais decorrentes das degradaçóes ocorridas no planeta. Contudo, destaca-se que a sustentabilidade compreende não somente na relação econômica e ambiental, mas na busca do equilíbrio humano frente aos demais desafios do mundo moderno.

Por esta analise, o objetivo é discutir contribuição da sustentabilidade para amenizar as consequências do crescimento global frente e a gradativa degradação ambiental. Isso é feito por meio do estudo do principio sustentabilidade, como direção finalística de consideráveis meios de soluçóes aos problemas desencadeados por essa globalização, com tendência às inovaçóes, seja de natureza científica ou de natureza jurídica, sempre em direção da primazia do progresso humano sustentável. Denota-se uma investigação de cunho linear, por meio da sustentabilidade que se lança no contexto mundial, com a primazia da preservação de recursos considerados essenciais para a continuidade existencial terrena. Por quais meios tende a ocorrer o ato da preservaçáo dos recursos naturais? Qual é a forma viável, diante da sociedade contemporânea, para que se possam obter respostas ao principio da sustentabilidade?

Com a ciência e a tecnologia buscam-se alternativas para preservar os recursos naturais ainda disponíveis e para reaver o restabelecimento de novos recursos ou substituir aqueles que estão extinção ou prestes a agregarem a decadência existencial; buscando meios que limitem as incertezas, as inseguranças quanto aos novos conceitos e as novas tecnologias. Um alerta prévio sobre os riscos ambientais, buscando melhores soluçóes cientificas para os problemas contemporâneos na seara ambiental.

O meio social tende haver mudanças de paradigmas, de valores, dos quais terão uma consciência racional ambiental em não degradar e, sim, evoluir preservando os recursos ainda existentes na finalidade de dignificar a vida da presente e futuras geraçóes.

O presente estudo está dividido em três momentos: no primeiro trata da sustentabilidade com uma quebra de paradigma em busca de um meio ambiente ecologicamente equilibrado e sadio. $\mathrm{O}$ segundo traz a discussão da sustentabilidade e sua concepçáo pluridimensional. O terceiro compreende as novas tecnologias no contexto da sociedade 
contemporânea sustentável, como uma contribuição a manutenção e existência da vida com qualidade.

Quanto à Metodologia, foi utilizada a base lógica Indutiva por meio da pesquisa bibliográfica a ser utilizada no desenvolvimento da pesquisa, compreende o método cartesiano quanto à coleta de dados e no relatório final o método indutivo com as técnicas do referente, da categoria, dos conceitos operacionais, da pesquisa bibliográfica e do fichamento.

Por fim, espera-se com este estudo contribuir para a reflexão sobre a sustentabilidade, sua efetivação por meio das inovações tecnológicas para a preservação do direito fundamental ao meio ambiente sadio e ecologicamente equilibrado, prevenindo-se, assim, a não degradação ecológica que garantirá a subsistência da vida humana terrena.

\section{Sustentabilidade: Uma Quebra de Paradigma em Busca de um Meio Am- biente Ecologicamente Equilibrado e Sadio}

O tema "sustentabilidade ${ }^{12}$ ", atualmente, não é mais um assunto restrito ao círculo de ambientalistas ou de profissionais especialistas em estudos sobre o meio ambiente. É discutido nas instituiçôes de ensino, segmentos financeiros, setores industriais, entidades representativas, em organizaçóes governamentais e não governamentais, o assunto integra todas as atividades.

Sustentabilidade é uma concepção que deriva de preservação, de restabelecimento social, econômico e ambiental do ecossistema ameaçado pelas atitudes insanas do ser humano. Uma forma de expressar uma preocupação em preservar, em conservar recursos naturais para uma geração presente e futura. $\mathrm{O}$ termo sustentabilidade significa a preservação de determinado bem, a conservação de determinado material ou matéria-prima para a fabricação do mesmo bem. É, ainda, conservação de determinados produtos, bens, materiais ou imateriais, com o intuito de não perdê-lo com o passar dos tempos, evitandose, assim, a escassez ou a extinção de bens necessários ${ }^{3}$.

1 Sobre o tema recomenda-se ver: SOUZA, Maria Claudia Silva Antunes de Souza; MAFRA, Juliete Ruana. A sustentabilidade no alumiar de Gabriel Real Ferrer: reflexos dimensionais na Avaliação Ambiental Estratégica In: SOUZA, Maria Claudia Silva Antunes de Souza; GARCIA, Heloise Siqueira Org(s). Lineamentos sobre sustentabilidade segundo Gabriel Real Ferrer.Itajaí: UNIVALI, 2014. p. 11-37. Disponível em: http://siaiapp28.univali.br/LstFree.aspx. Acesso em: 20 de março de 2015.

2 Sobre o tema a leitura: SOUZA, Maria Cláudia S. Antunes de; MAFRA, Juliete R. .A Sustentabilidade e o ciclo do bem estar: o equilíbrio dimensional e a ferramenta da avaliaçáo ambiental estratégica. Nomos (Fortaleza), v. 34, 2014. p. 345-366.

3 DIAS, Bruno Smolarek; MARDEGAN, Herick. Sustentabilidade como fundamento da cidadania transnacional. Revista Eletrônica Direito e Política, Programa de Pós-graduação Stricto Sensu em Ciência Jurídica da UNIVALI, Itajaí, V.6, n.2, 2º quadrimestre de 2011. Disponível em: WWW.univali.br/ direitopolitica - ISSN 1980-7791, p. 604/605. 
Bruno Smolarek Dias refere o que compóe o termo sustentabilidade, expressando que, "ao consumir sustentavelmente, dá-se a possibilidade da garantia de renovação do produto, ou seja: oportuniza-se a existência do mesmo produto por um maior período de tempo, visando à aplicabilidade do meio ambiente sustentável as tão aclamadas futuras geraçóes" ${ }^{4}$.

A sustentabilidade deve ser pensada numa perspectiva global, envolvendo todo o planeta, com equidade, fazendo que o bem de uma parte não se faça à custa do prejuízo da outra. A Sustentabilidade, assim, passa a ser o conjunto de mecanismos necessários à manutenção de algo sem que gere danos (ou, pelo menos, os reduza) no ambiente referenciado, também levando em consideração os demais ambientes para que haja uma intenção de perfeito equilíbrio entre eles, não se privilegiando um em detrimento dos demais.

No século XXI, várias atuaçôes humanas - Protocolo Estocolmo5 ${ }^{5}$, Rio 92, Rio +20 perfazem a importância da conservação dos meios naturais como fonte de sobrevivência. O progresso, seja ele econômico social ou cultural, ressalta a essencialidade da sustentabilidade ambiental, a qual transcende formas de uso racional quanto ao meio natural, objetivando resguardar o direito a uma vida digna e saudável para as geraçóes futuras.

As tendências atuais são insustentáveis e, se faz necessário, revertê-las para garantir um futuro mais saudável para as próximas gerações. Com este pensamento, a Comissão

4 DIAS, Bruno Smolarek; MARDEGAN, Herick. Sustentabilidade como fundamento da cidadania transnacional. Revista Eletrônica Direito e Política, Programa de Pós-graduação Stricto Sensu em Ciência Jurídica da UNIVALI, Itajaí, V.6, n.2, 20 quadrimestre de 2011. Disponível em: WWW.univali.br/ direitopolitica - ISSN 1980-7791, p. 605.

5 Em 1972, por consequência, convocou-se a Conferência das Naçôes Unidas para o Meio Ambiente Humano, realizada em Estocolmo, que produziu a Declaração sobre Ambiente Humano, estabelecendo princípios para questốes ambientais internacionais, incluindo direitos humanos, gestão de recursos naturais, prevenção da poluição, dando surgimento ao direito ambiental internacional, elevando a cultura política mundial de respeito à ecologia, e servindo como o primeiro convite para a elaboração de novo paradigma econômico e civilizatório para os países. Na reuniấo de Estocolmo, originou-se o momento de constatação e alerta global sobre a degradação ambiental. A Declaração da Conferência da ONU sobre o Meio Ambiente descreveu assim: "defender e melhorar o meio ambiente para as atuais e futuras geraçóes se tornou uma meta fundamental para a humanidade". Deste modo, a conferência de Estocolmo criou a Comissão Mundial sobre Meio Ambiente e Desenvolvimento, inaugurando a agenda ambiental, permitindo iniciar a relação entre ambiente e desenvolvimento, dando as primeiras referências de Desenvolvimento Sustentável, que na época tinha por termo "ecodesenvolvimento". Tratou-se dos primeiros passos para o pensamento verde. Em 1983, o Relatório de Brundtland, feito pela chefe da Comissão Mundial do Meio Ambiente e Desenvolvimento, conceituou Desenvolvimento Sustentável como: "a satisfação das necessidades do presente sem comprometer a capacidade das geraçóes futuras de satisfazer em suas próprias necessidades". O Relatório complementa que: "um mundo onde a pobreza e a desigualdade são endêmicas estará sempre propenso à crises ecológicas, entre outras", “o Desenvolvimento Sustentável requer que as sociedades atendam às necessidades humanas tanto pelo aumento do potencial produtivo como pela garantia de oportunidades iguais para todos". Relatório da Comissão Mundial sobre Meio Ambiente e Desenvolvimento. Relatório Brundtland, "Nosso Futuro Comum. Disponível em: http://www.un.org/ documents/ga/res/42/ares42-187.htm. Acesso em: 15 de fevereiro de 2015. 
Mundial sobre Meio Ambiente e Desenvolvimento das Naçóes Unidas publicou o conhecido "Relatório de Brundtland", em 1987, denominado como "Nosso Futuro Comum" buscando atender às necessidades humanas, ao garantir a equidade global para as geraçóes presentes e futuras, através da redistribuição dos recursos para as naçóes mais pobres e pela conservação ambiental; reforçando a necessidade de repensar a postura do homem diante do meio ambiente, provocando reflexôes sobre o desenvolvimento sustentável.

Em que pese ter passado mais de duas décadas é necessário ainda, avançar muito para alcançar o equilíbrio multidimensional preconizado pelo principio da sustentabilidade.

José Henrique de Faria relaciona sustentabilidade com base em quatro princípios, conforme os relatórios da Organização das Naçóes Unidas (ONU), que assim dispóe:

A sustentabilidade estaria baseada em quatro princípios: (i) princípio precatório: determinaria que onde houvesse possibilidade de prejuízos sérios á saúde dos seres vivos, a ausência de certeza científica não deveria adiar medidas preventivas; (ii) princípio preventivo: os riscos e danos ambientais deveriam ser evitados o máximo possível e ser avaliados previamente, como objetivo de escolher a solução adotada; (iii) princípio compensatório: compensações para vítimas da poluição e outros danos ambientais deveriam estar previstas na legislaçáo; (iv) princípio do poluidor pagador: os custos da reparação ambiental e das medidas compensatórias deveriam ser suportadas pelas partes responsáveis?

O autor aporta à sustentabilidade sob vários fatores, cada qual com seus conceitos e características, ensejando ainda mais sua importância no atual contexto socioambiental. Assim dispôs:

O conceito de sustentabilidade comportaria sete aspectos principais: (i) sustentabilidade social: melhoria da qualidade de vida da população, equidade na distribuição de renda e de diminuição das diferenças sociais, com participação e organização popular; (ii) sustentabilidade econômica: públicos e privados, regularização do fluxo desses investimento, compatibilidade entre padrôes de produção e consumo, equilíbrio de balanço de pagamento, aceso á ciência e tecnologia; (iii) sustentabilidade ecológica: o uso dos recursos naturais deve minimizar danos aos sistemas de sustentação da vida: redução dos resíduos tóxicos e da poluição, reciclagem de materiais e energia, conservação, tecnologias limpas e de maior eficiência e regras para uma adequada proteção ambiental; (iv) sustentabilidade

6 Relatório da Comissão Mundial sobre Meio Ambiente e Desenvolvimento. Relatório Brundtland, "Nosso Futuro Comum. Disponível em: http:/www.un.org/documents/ga/ res/42/ares42-187.htm. Acesso em: 15 de fevereiro de 2015.

7 NEVES, Lafaiete Santos (org). Sustentabilidade. Anais de textos selecionados do V seminário sobre Sustentabilidade. Curitiba: Juruá, 2011, p. 16. 
cultural: respeito aos diferentes valores entre os povos e incentivo a processos de mudança que acolham as especificidades locais; (v) sustentabilidade espacial: equilíbrio entre o rural e o urbano, equilíbrio de migraçôes, desconcentração das metrópoles, adoção de praticas agrícolas mais inteligentes e não agressivas á saúde e ao ambiente, manejo sustentável das florestas e industrialização descentralizada; (vi) sustentabilidade política; no caso do Brasil, a evolução da democracia representativa para sistemas descentralizados e participativos, construção de espaços públicos comunitários, maior autonomia dos governos locais e descentralização da gestấo de recursos; (vii) sustentabilidade ambiental: conservação geográfica, equilíbrio de ecossistemas, erradicação da pobreza e da exclusão, respeito aos direitos humanos e integração social ${ }^{8}$.

A ideia de um mundo sustentável está nas mudanças, na quebra de paradigma do estado de sobrevivência com a preservação do entorno natural para que haja uma solidificação do direito à vida com sobreposição da dignidade humana. Nas palavras de Fritjof Capra perfaz que "as novas concepções da física têm gerado uma profunda mudança em nossas visóes de mundo; da visão de mundo mecanicista de Descartes e de Newton para uma visão holística, ecológica"”.

O principio da sustentabilidade é uma inversão de valores sociais que, a partir de sua importância para com o desenvolvimento da espécie humana, tende a fortificar-se para garanti-la do bem estar social frente aos anseios naturais. Na mesma linha Fritjof Capra aduz que:

(...) o que estamos vendo é uma mudança de paradigmas que está ocorrendo não apenas no âmbito da ciência, mas também na arena social, em proporçôes ainda mais amplas. Para analisar essa transformação cultural, generalizei a definição de Kuhn de um paradigma científico até obter um paradigma social, que defino como "uma constelação de concepçóes, de valores, de percepçóes e de práticas compartilhados por uma comunidade, que dá forma a uma visão particular da realidade, a qual constitui a base da maneira como a comunidade se organiza ${ }^{10}$.

A sua origem é de suma importância, a qual ressalta a essencialidade de um direito fundamental, pois está estritamente ligada à conservação de um bem substancial. Nesse sentido, é dito por Gabriel Real Ferrer como um "direito difuso" diante de sua abrangência quanto aos titulares desse direito que é o meio ambiente. No texto Constitucional, há

8 NEVES, Lafaiete Santos (org). Sustentabilidade. Anais de textos selecionados do V seminário sobre Sustentabilidade. Curitiba: Juruá, 2011, p. 17.

9 CAPRA, Fritjof. A Teia da vida: uma nova compreensão científica dos sistemas vivos. Tradução Newton Roberval Eichemberg. 4. ed. São Paulo: Cultrix, 1999, p.24

10 CAPRA, Fritjof. A Teia da vida: uma nova compreensáo científica dos sistemas vivos. Tradução Newton Roberval Eichemberg. 4. ed. São Paulo: Cultrix, 1999, p.24,25. 
expressa menção do direito ao meio ambiente como uma norma fundamental, normatizado no artigo 225 da Carta Constitucional"11, que anuncia ser um "direito de todos a um meio ambiente ecologicamente equilibrado" 12 .

Dessa natureza, tem-se a designação de um dos objetivos fundamentais da Constituição da República Federativa do Brasil, como norma instituidora dos fundamentos decorrentes do direito a um meio ambiente sadio como um direito fundamental do indivíduo. Há, dessa forma, a necessidade de haver uma quebra de paradigma, de conceito inalterado, estando os reflexos do desenvolvimento racional batendo às portas do modo de vida dos seres humanos.

$\mathrm{Na}$ era da vez, a sustentabilidade, seus conceitos, as reflexóes há embates e debates em torno da palavra mais expressada pelos operadores do Direito, dos Estados, das organizaçóes. Enfim, fala-se e discute-se muito sobre o desenvolvimento sustentável, a sustentabilidade econômica e/ou ambiental, crescimento sustentável e, diante de várias outras denominaçóes, busca-se a realidade conceitual dessa expressão, hoje, universal.

Como forma unilateral, simplificada, tem-se a intenção de afirmar que o seu real significado tem fundamento na preservação dos meios naturais para uma subsistência digna no futuro. Há preocupação com o equilíbrio social, com a baixa poluição, com a escassez de alimentos, com os meios de transportes mais adequados ao meio ambiente, com a falta de água potável, enfim, com o agir, o pensar e o concretizar açóes humanas que garantam uma vida com qualidade digna, sem comprometer o presente e, consequentemente, o futuro. Chegou-se na era de agir com racionalidade.

Na visão de José Roque Junges, o assunto à preservação do entorno natural reside nas visóes antropocentrismo e biocentrismo.

O antropocentrismo débil ou mitigado admite que existam deveres do homem para com a natureza, elenca assim uma responsabilidade da raça humana para com a natureza, emergindo o cuidado com as futuras geraçôes. Por isso são estabelecidos como marcos desta tendência os interesses humanos, suas necessidades e preferências, relegando a um segundo plano a natureza em si ou seu equilíbrio ou harmonia. (...) O biocentrismo apresenta-se como outra grande tendência, pela qual existe a visão da natureza como titular de direitos. Na posiçáo biocêntrica existem deveres do homem para com o meio ambiente, existe a consideração de um valor

11 BRASIL. Constituiçáo da República Federativa do Brasil. Art. 225. Todos têm direito ao meio ambiente ecologicamente equilibrado, bem de uso comum do povo e essencial à sadia qualidade de vida, impondo-se ao Poder Público e à coletividade o dever de defendê-lo e preservá- lo para as presentes e futuras gerações. Disponível em: http://www.planalto.gov.br/ccivil_03/constituicao/constitui\%C3\%A7ao. htm. Acessado em 19 de março de 2015.

12 BRASIL, Constituição da República Federativa do Brasil. Disponível em: http://www.planalto.gov.br/ ccivil_03/constituicao/constitui\%C3\%A7ao.htm. Acessado em 19 de março de 2015. 
intrínseco para a natureza, rejeitando-se a diferenciação entre humanos e não-humanos ${ }^{13}$.

O termo sustentabilidade não paira seus fundamentos em questôes de cunho ambiental tão somente, mas, sim, seus reflexos de desenvolvimento racional, o qual garanta o mesmo para geraçóes futuras, tem, no direito ambiental, apenas um de seus alicerces, sendo um conceito amplo, denso, ao que se enquadra no contexto social. Quanto à ideia mencionada, Saulo de Oliveira Pinto Coelho declara:

O aspecto ambiental da sustentabilidade está altamente em voga na atualidade pelo crescente número de catástrofes naturais que, acredita-se, sejam causadas (em parte, pelo menos) por culpa do homem. Essa é a razão pela qual se busca estabelecer o uso racional dos meios naturais pelo homem, sem que isso represente uma destruição da natureza. (...) Em suma: a sustentabilidade não implica apenas em minimizar os dados que os empreendimentos humanos geram no meio ambiente; implica, certas vezes, em se tomar a decisão política de se impedir ou limitar um empreendimento, em nome da proteçáo solidaria do bem-estar presente e futuro. Como já foi dito a sustentabilidade não visa apenas o benéfico do meio ambiente. $\mathrm{Na}$ verdade, o meio beneficio de açōes sustentáveis para a Constituição Federal é o próprio ser humano ${ }^{14}$.

O fenômeno da sustentabilidade é a busca do equilíbrio em qualquer esfera do desenvolvimento, seja ele econômico, político ou social. Aparente degradação ambiental faz com que haja a racionalização dos atos humanos para com os meios naturais. Nessa perspectiva de reserva dos recursos, de proteção ao meio natural, de preservação das fontes consideradas vitais à sobrevivência humana - ar, água, meios naturais (terra) - revela-se a proteção ao direito fundamental à vida. Nesse sentido, a vida deve ser vivenciada de forma digna, com equilíbrio dos meios naturais, resultando como resposta aos ditames que clamam a sociedade.

Ainda, quanto à sustentabilidade, tem-se que reflete um desenvolvimento voltado para a preocupação com o futuro. A era capitalista, na qual o consumo é a matriz social, percorre de maneira incontrolável a reaçáo/ação do homem com o meio social, causando temores quanto à sua continuidade, caso algo náo se modifique. Deve haver uma revalorização de maneiras, uma nova forma de atuar na civilização, para que haja perspectivas de um futuro sustentável, com recursos naturais mínimos ao desenvolvimento do próprio ser humano.

13 JUNGES, José Roque. Ética ambiental. São Leopoldo: Unisinos, 2004. p. 13-23.

14 COELHO, Saulo de Oliveira Pinto; ARAÚJO, André Fabiano Guimarães de. A sustentabilidade como princípio constitucional sistêmico e sua relevância na efetivaçáo interdisciplinar da ordem constitucional econômica e social: para além do ambientalismo e do desenvolvimentismo. Revista da Faculdade de Direito de Uberlândia, v. 39:261-291, de 2011. 
Segundo Leila Ribeiro Mariano, a sustentabilidade deve ser compreendida por meio de um conceito ecológico, o qual tem a capacidade de atender às necessidades de um grupo social no território em que se vive. Da mesma forma, como um conceito político, em razão do qual a sociedade tem competência de organizar-se por si própria, delimitando o crescimento conquanto suas condiçôes aos recursos naturais, dos meios tecnológicos e do nível efetivo ao bem-estar social ${ }^{15}$.

O principio da sustentabilidade, conforme sua acuidade no contexto social contemporâneo tem a perspectiva principiológica não somente no domínio ambiental, mas, também, interdisciplinar. Neste contexto, adota-se o entendimento da sustentabilidade como principio norteador dos demais princípios que regem o ordenamento jurídico, no que diz respeito meio ambiente sadio e equilibrado.

\section{A Sustentabilidade e as sua Concepção Pluridimensional}

A Sustentabilidade consiste no pensamento de capacitação global para a preservação da vida humana equilibrada, consequentemente, da proteção ambiental, mas não só isso, também da extinção ou diminuição de outras mazelas sociais que agem contrárias a esperança do retardamento da sobrevivência do homem na Terra ${ }^{16}$.

As diferenças entre Sustentabilidade e Desenvolvimento Sustentável ${ }^{17}$ afloram com um processo em que a primeira se relaciona com o fim, enquanto o segundo com o meio. O Desenvolvimento Sustentável como meio para que seja possível obter equilíbrio entre o progresso, a industrialização, o consumo e a estabilidade ambiental, como objetivo a Sustentabilidade e o bem estar da sociedade.

Nesse alcance doutrinário que se quer construir fundamentos para que a sociedade insira nos seus valores éticos, sociais que o progresso tenda a desenvolver-se com os olhos voltados para o futuro sustentável.

"O desenvolvimento que importa é aquele que se constitui mutuamente com a sustentabilidade, condicionado por ela ${ }^{18}$. $\mathrm{O}$ ato de crescer, seja na área social, econômica

15 MARIANO, Leila. O poder judiciário e a sustentabilidade. In: FLORES, Nilton César (Org.). A sustentabilidade ambiental e suas múltiplas faces. Campinas: Millennium, 2012. p. 36.

16 SOUZA, Maria Cláudia da Silva Antunes de Souza. 20 anos de Sustentabilidade: reflexôes sobre avanços e desafios. Revista da Unifebe. 2012; 11 (dez): 239-252. Disponível: http://www.unifebe.edu.br/revistaeletronica/. Acesso em 15 fevereiro de 2014.

17 Sobre o tema recomenda-se a leitura: SOUZA, Maria Cláudia Silva Antunes de; SOUZA, Greyce Kelly Antunes. Sustentabilidade e Sociedade de Consumo: avanços e retrocessos. In: SOUZA, Maria Cláudia Silva Antunes de. ARMADA, Charles Alexandre Souza. Teoria Juridica e Transnacionalidade. Vol. I. Itajaí: UNIVALI.

18 FREITAS, Juarez. Sustentabilidade: direito ao futuro. Belo Horizonte: Fórum, 2012, p. 49. 
ou humana, tem que estar adjetivado à sustentabilidade que se constitui de garantizar a qualidade de vida, o bem-estar para geraçóes presentes e futuras.

O desenvolvimento sustentável definido pela primeira vez e, depois, incorporado nos mais diversos textos é aquele que tende a preservar meios naturais às geraçóes, sejam presentes, sejam futuras. Trata-se de uma forma de garantir, através de seus progressos, um modo com vida, por meio dos recursos naturais, com qualidade para a existência humana.

Juarez Freitas conceitua a sustentabilidade:

Eis o conceito proposto para o princípio da sustentabilidade: trata-se do princípio constitucional que determina, com eficácia direta e imediata, a responsabilidade do Estado e da sociedade pela concretização solidária do desenvolvimento material e imaterial, socialmente inclusivo, durável e equânime, ambientalmente limpo, inovador, ético e eficiente, no intuito de assegurar, preferencialmente de modo preventivo e precavido, no presente e no futuro, o direito ao bem-estar ${ }^{19}$.

Ainda, Juarez Freitas, anuncia elementos indispensáveis para um conceito operacional de sustentabilidade eficaz:

(1) a natureza de princípio constitucional diretamente aplicável, (2) a eficácia (encontro de resultados justos, não mera aptidáo para produzir efeitos (jurídicos), (3) a eficiência (o uso de meios idôneos), (4) o ambiente limpo (descontaminado e saudável), (5) a probidade (inclusão explicita da dimensão ética), (6) a prevenção (dever de evitar danos certos), (7) a precaução (dever de evitar danos altamente prováveis), (8) a solidariedade intergeracional, com o reconhecimento dos direitos das geraçóes presentes e futuras, (9) o bem-estar (acima das necessidades materiais). Nenhum desses elementos pode faltar ao conceito, sob pena de reducionismo indesejável ${ }^{20}$.

Quanto à sustentabilidade, Juarez Freitas, ao afirmar que a sustentabilidade molda o desenvolvimento, declara que ela "é multidimensional, porque o bem-estar é multidimensional”, sendo ambiental, social, econômica, ética e jurídico-política.

No que diz respeito à dimensão social, pensa-se na formalização dos direitos fundamentais sociais, na igualdade de condiçóes sociais. Na realidade socioeconômica, a inquietação em desfavor das desigualdades é crescente. Aqueles que nada percebem com as devastaçóes ambientais encontram-se em cenários vitais diversos. A busca pela justiça social é uma premissa fundamental do princípio da sustentabilidade ${ }^{21}$, pois é nas camadas

19 FREITAS, Juarez. Sustentabilidade: direito ao futuro. Belo Horizonte: Fórum, 2012, p. 41.

20 FREITAS, Juarez. Sustentabilidade: direito ao futuro. Belo Horizonte: Fórum, 2012, p. 41.

21 AUMOND, Juarêz. As perspectives do desenvolvimento sustentável. IN BENEVIDES, Mario e VALDEZ, Silvia (org.). Nós e a sustentabilidade. Florianópolis: Relata, 2012, p. 175. 
sociais pobres que se sentem os efeitos da crise ambiental. O problema dos direitos sociais é uma realidade concreta verificada nas escolas, nas empresas pelos trabalhadores, nas áreas de saúde, tornando-se uma situação insustentável. O que se pretende é a busca pela melhoria na qualidade de vida por meio da inclusão social.

Com relação à dimensão econômica, tem-se que ela está relacionada ao consumo e à produção, os quais necessitam ser reestruturados. A forma de acumular riquezas não deve estar condicionada à agressão de recursos naturais. "A natureza não pode ser vista como simples capital22". A responsabilidade comum dos Estados e cidadãos para a defesa ambiental tem que reaver meios eficazes e eficientes para o crescimento econômico não calcado no meio natural.

A dimensão jurídico-político condiciona a sustentabilidade à tutela jurídica ao direito ao futuro, que visa a garantir o bem-estar de titulares existentes e os ainda não existentes, de proteger a qualidade de vida para as presentes e para as futuras geraçôes. Nos anseios normativos, depara-se a sustentabilidade que emerge de normas que se projetam para a defesa ambiental. No que tange aos aspectos políticos da sustentabilidade, esta se relaciona com as políticas públicas, sendo a forma pela qual o Poder Público comunica-se com o meio social. Essas políticas públicas devem atender ao aspecto da solidariedade ao serem externadas ao mundo social, não havendo desigualdades em suas efetivaçôes. Saulo de Oliveira Pinto Coelho e André Fabiano Guimarães de Araújo explicam que há outros aspectos do princípio da sustentabilidade no plano político, afirmando que as políticas públicas devem ser tratadas de forma sinergética umas com as outras; que as políticas públicas sejam autônomas em sua prática, não precisando de custeio assistencialista; que as políticas públicas promovam solidariedade social, com direção à implementação da dignidade da pessoa humana ${ }^{23}$.

A dimensão ética está no interior de cada ser humano, de cada atitude humana. A solidariedade, a coletividade no pensar, no agir deve transcender o direito ao mínimo existencial, formalizando a base jurídica fundamental a dignidade da pessoa humana. A frase "pensar localmente e agir globalmente", não está só para aplicação de regras e princípios transnacionais, mas, sim, nas atitudes de cada ser humano para com o meio ambiente, sendo esta um direito humano fundamental e difuso.

$\mathrm{Na}$ forma de agir eticamente e de forma sustentável é aquela "que consiste em agir de modo tal que possa ser universalizada a produção do bem-estar duradouro, no íntimo e na interação com a natureza ${ }^{24 "}$.

22 FREITAS, Juarez. Sustentabilidade: direito ao futuro. Belo Horizonte: Fórum, 2012, p. 54.

23 COELHO, Saulo de Oliveira Pinto; ARAÚJO, André Fabiano Guimarães de. A sustentabilidade como princípio constitucional sistêmico e sua relevância na efetivaçáo interdisciplinar da ordem constitucional econômica e social: para além do ambientalismo e do desenvolvimentismo. Revista da Faculdade de Direito de Uberlândia, v. 39:261-291, de 2011. Disponível em: http://www.revista. fadir.ufu.br/viewissue.php?id=7. Acessado em agosto de 2012, p. 272.

24 FREITAS, Juarez. Sustentabilidade: direito ao futuro. Belo Horizonte: Fórum, 2012, p. 61. 
Por fim, a dimensão ambiental é aquela constitucionalizada no artigo 225 da Constituição da republica Federativa do Brasil, o qual declara o direito fundamental a um meio ambiente sadio e ecologicamente equilibrado para as sociedades atuais e futuras. $\mathrm{O}$ direito a um meio ambiente limpo, saudável, produtor de recursos naturais indispensáveis para a vida humana ${ }^{25}$. Os desastres, as poluições de rios, mares, solo e atmosfera já resultaram em grandes desconfortos sociais, não havendo outra saída a não ser a inserção do princípio da sustentabilidade como condutor de resultados positivos quanto a esse aspecto socioambiental.

A dimensão ambiental é aquela que garante a proteção do sistema planetário, para manter as condições que possibilitam a vida na Terra. De acordo com Ferrer $^{26}$, é necessário desenvolver normas globais, de caráter imperativo, para que essa dimensão seja eficaz.

Os estudos de Juarez Freitas traduzem, de forma ímpar, a dimensão ambiental da sustentabilidade:

Não pode haver qualidade de vida e longevidade digna em ambiente degradado e, que é mais importante, no limite, (b) não pode sequer haver vida humana sem o zeloso resguardo da sustentabilidade ambiental, em tempo útil, donde segue que (c) ou se protege a qualidade ambiental ou, simplesmente, não haverá futuro para nossa espécie ${ }^{27}$.

São dimensóes que, ao se ligarem, modulam a sustentabilidade, não podendo ser rompidas. Esse fenômeno da sustentabilidade é uma forma diferenciada de viver. A existência humana está atrelada à formalização dessas dimensôes que corporificam o ato de ser sustentável. O princípio da sustentabilidade correspondente às mudanças humanas tende a universalizar os direitos essenciais, para que a vida terrena tenha continuidade com qualidade e bem-estar.

Corrobora Gabriel Real Ferrer ${ }^{28}$ que a sustentabilidade além do tripé das dimensóes tradicionais: a social, a econômica e a ambiental, destaca uma quarta dimensão a "tecnológica”, a qual determina a forma de sociedade com suas evoluçóes, conhecimentos e técnicas. Não há possibilidade de haver uma sustentabilidade parcial de determinada região, Estado ou País, mas sim, na expectativa de haver uma diminuição da agressão aos

25 AUMOND, Juarêz. As perspectives do desenvolvimento sustentável. IN BENEVIDES, Mario e VALDEZ, Silvia (org.). Nós e a sustentabilidade. Florianópolis: Relata, 2012, p. 173.

26 FERRER, Gabriel Real. Calidad de vida, médio ambiente, sostenibilidad y ciudadanía. Construímos juntos el futuro? Revista NEJ - Eletrônica, Vol. 17 - n. 3 - p. 319 / set-dez 2012 321. Disponível em: www.univali.br/periodicos. Acesso em 19 de março de 2015.

27 FREITAS, Juarez. Sustentabilidade: direito ao futuro. Belo Horizonte: Fórum, 2012, p. 65.

28 FERRER, Gabriel Real. Calidad de vida, médio ambiente, sostenibilidad y ciudadanía. Construímos juntos el futuro? Revista NEJ - Eletrônica, Vol. 17 - n. 3 - p. 319 / set-dez 2012 321. Disponível em: www.univali.br/periodicos. Acesso em 19 de março de 2015. 
meios naturais, com a consequente diminuição de consumo e produção global será, cada vez mais, possível chegar-se em torno do que é ser um estado sustentável ${ }^{29}$.

Com o controle da distribuição de riquezas e com a diminuiçãa da produção e do consumo, haverá meios de resguardar, ao ser humano, em um meio ambiente natural ou artificial, uma qualidade de vida digna, condizente com os direitos humanos fundamentais do ser humano.

Ingo Wolfgang Sarlet e Tiago Fensterseifer declaram que:

[...] tanto sob a perspectiva individual quanto coletiva, a própria noção de sustentabilidade deve ser tomada a partir dos eixos econômicos, social e ambiental. tais eixos, contudo, devem ser concebidos e aplicados de forma isonômica e equilibrada, refutando-se, consoante já frisado, toda e qualquer hierarquização prévia, notadamente pelo fato de que é no conjunto que tais dimensôes se prestam à promoçáo de uma existência digna ${ }^{30}$.

A sociedade atual, com sua primazia capitalista - consumo exacerbado -, organizase em relação às inovaçóes tecnológicas, moldando-se conforme se insere nas inovaçóes. Não se tem a intenção de promover a tecnologia para aumentar os meios de renda, de acúmulo de capitais e de poder dos estados, mas, sim, como meio de adentrar ao mundo, ao fenômeno da sustentabilidade.

Neste estudo, almeja-se fomentar uma reflexão sobre os aspectos inovadores da ciência e das novas tecnologias, no sentido de propiciarem um mundo ecológico com condiçôes de vida, com justiças sociais, com manutençẫo da saúde humana, como meios de saneamento eficazes para a vida humana. Dessa forma, a ilustração gráfica quanto às dimensôes da sustentabilidade conquanto às inovaçôes tecnológicas, assim se configura:

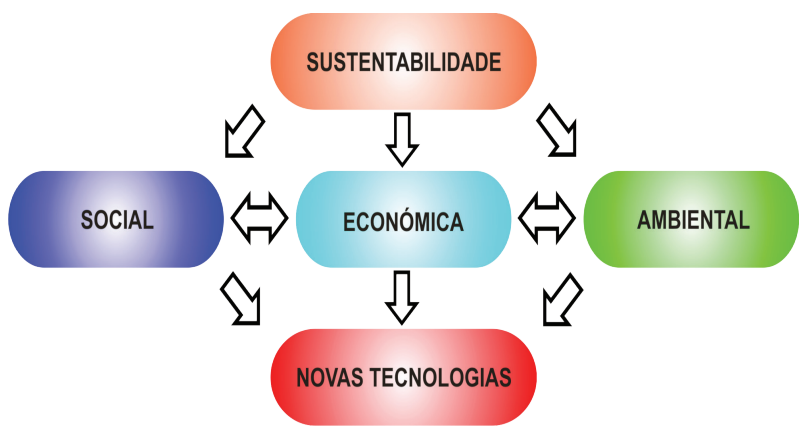

29 FERRER, Gabriel Real. Calidad de vida, médio ambiente, sostenibilidad y ciudadanía. Construímos juntos el futuro? Revista NEJ - Eletrônica, Vol. 17 - n. 3 - p. 319 / set-dez 2012 321. Disponível em: www.univali.br/periodicos. Acesso em 19 de março de 2015.

30 SARLET, Indo Wolfgang; FENSTERSEIFER, Tiago. Estado socioambiental e mínimo existencial (ecológico): algumas aproximaçôes. SARLET, Ingo Wolfgang. Estado socioambiental e direitos fundamentais. Porto Alegre: Livraria do Advogado, 2010, p. 25. 
$\mathrm{Na}$ ânsia pelo desenvolvimento econômico, as naçóes organizam-se em razão de uma cooperação comum. Uma forma de crescimento que vem buscando novas alternativas, como o desenvolvimento sustentável, com o intuito de conciliar o progresso integral, a preservação do meio ambiente e a melhoria na qualidade de vida.

Gabriel Real Ferrer aduz sobre as novas tecnologias:

Ponhamos a ciência e a técnica ao serviço do objetivo comum. Não só os novos conhecimentos devem nos ajudar a corrigir erros passados, como por exemplo, mediante a captação de $\mathrm{CO} 2$, ou a contribuir soluções eficazes a problemas como os que propóem uma civilização energético-dependente, senão que indefectiblemente a tecnologia disponível determina os modelos sociais em os que nos desenvolvemos, tal como insistentemente demonstra a história ${ }^{31}$.

Não há dúvida de que a tecnologia quem transmuda a sociedade, pois esta se depara com os avanços e, por meio deles, conduz suas expectativas de vida. Uma vida digna, de bem-estar, não está configurada no poder de maior aquisição de bens e consumo, mas na qualidade de vida quanto à saúde, à alimentação, ao saneamento básico, às condições de pureza do ar, da terra e da água, nas condiçóes e dos meios para a produção de bens que garantam a dignidade do ser humano. Não basta ter-se riqueza, acúmulo de capitais, se não houver condiçôes de existências de vida.

Pergunta-se: Qual das tecnologias que poderá mudar a sociedade, ou a forma de pensar social? Uma ciência, uma inovação que venha a politizar os efeitos tecnológicos, tornar disponíveis para todos os seres humanos os efeitos dessas inovações científicas. A ciência e a técnica estão a serviço do homem e da sustentabilidade. Assim, elas deveriam prover os modelos sociais que propiciam um novo saber tecnológico e possibilitam a criação de novos sistemas de governança.

Por meio dos estudos, aponta-se, nesta pesquisa, que as inovaçóes tecnológicas estáo a serviço do paradigma da sustentabilidade como resposta à recomposição ecológica, à preservação da base ecológica. Da mesma forma, são um meio de possibilitar um avanço humano global quanto à qualidade existencial de vida frente às catástrofes ambientais que, cada vez mais, comprometem a vida terrena.

31 FERRER, Gabriel Real. Calidad de vida, médio ambiente, sostenibilidad y ciudadanía. Construímos juntos el futuro? Revista NEJ - Eletrônica, Vol. 17 - n. 3 - p. 319 / set-dez 2012 321. Disponível em: www.univali.br/periodicos. Acesso em 15 fevereiro de 2014. [Tradução livre pelas autoras] - Pongamos la ciencia y la técnica al servicio del objetivo común. No sólo los nuevos conocimientos deben ayudarnos a corregir errores pasados, como por ejemplo mediante la captación de $\mathrm{CO} 2$, o a aportar soluciones eficaces a problemas como los que plantea una civilización energético-dependiente, sino que indefectiblemente la tecnología disponible determina los modelos sociales en los que nos desarrollamos, tal como insistentemente demuestra la historia. 
$\mathrm{Na}$ ciência e na tecnologia encontram-se as respostas para reorganizar a situação global quanto à crise ambiental, saindo da ideia de uma dimensão da sustentabilidade e, sim, como uma resposta aos problemas ambientais atuais, de forma global, para a inserção concreta do paradigma da sustentabilidade.

José Eli da Veiga declara que "a sustentabilidade ambiental de qualquer estilo de crescimento econômico que possa ser imaginado depende de descobertas científicas, novas tecnologias e consequentes inovaçóes; e provavelmente venha delas depender cada vez mais ${ }^{32}$ ".

A sustentabilidade é um adjetivo ao ato de desenvolvimento, referindo-se ao fato de que o progresso econômico possa ser compatível com a conservação dos ecossistemas, equilibrando e harmonizando a forma de progresso com a base ecológica sadia. Não há como haver uma separação do meio ambiente para com a vida humana, sendo que um transcende a fundamentalidade de existência do outro. O autor Fritjof Capra ao conceituar o que vem a ser ecologia profunda, faz esta relação entre o ser humano e o entorno natural.

A ecologia rasa é antropocêntrica, ou centralizada no ser humano. Ela vê os seres humanos como situados acima ou fora da natureza, como a fonte de todos os valores, e atribui apenas um valor instrumental, ou de "uso", à natureza. A ecologia profunda não separa seres humanos — ou qualquer outra coisa - do meio ambiente natural. Mundo não como uma coleção de objetos isolados, mas como uma rede de fenômenos que estão fundamentalmente interconectados e são interdependentes. A ecologia profunda reconhece o valor intrínseco de todos os seres vivos e concebe os seres humanos apenas como um fio particular na teia da vida ${ }^{33}$.

Nessa concepção que a sustentabilidade, como meio indutor ao desenvolvimento sustentável que garantirá a preservação dos recursos naturais indispensáveis para a existência humana, denota-se um fusão de paradigma conquanto às atitudes humanas para com o meio ambiente.

Toda a questão dos valores é fundamental para a ecologia profunda; é, de fato, sua característica definidora central. Enquanto que o velho paradigma está baseado em valores antropocêntricos (centralizados no ser humano), a ecologia profunda está alicerçada em valores ecocêntricos (centralizados na Terra). É uma visão de mundo que reconhece o valor inerente da vida não-humana. Todos os seres vivos são membros de comunidades ecológicas ligadas umas às outras numa rede de interdependências. Quando essa percepção ecológica profunda torna-se parte de

32 VEIGA, José Eli da. Sustentabilidade: a legitimação de um novo valor. São Paulo: Editora SENAC, 2012, p. 67/68.

33 CAPRA, Fritjof. A Teia da vida: uma nova compreensão científica dos sistemas vivos. Traduçấo Newton Roberval Eichemberg. 4. ed. Sáo Paulo: Cultrix, 1999, p.25-26. 
nossa consciência cotidiana, emerge um sistema de ética radicalmente novo $^{34}$.

O desenvolvimento sustentável justifica-se na ideia reflexiva da sustentabilidade na seara ambiental. Isso tendo em vista que o resguardo, a preservação de um meio ambiente sadio e equilibrado, com o seu consequente não esgotamento para a sobrevida das geraçóes futuras, ressaltam quão importante sãos seus fundamentos para a preservação da vida em um planeta ecologicamente equilibrado.

\section{As Novas Tecnologias no Contexto da Sociedade Contemporânea - Sus- tentável. 0 Avanço Tecnológico e seus Reflexos na Era do Século XXI}

$\mathrm{Na}$ esfera doutrinária do desenvolvimento sustentável, exigem-se mudanças nos valores que orientam os comportamentos sociais, agregando o conhecimento e a inovaçáo de tecnologia para que haja a solução da crise ambiental ${ }^{35}$. A natureza morta não serve ao ser humano; a ideia de utilização dos recursos naturais deve estar subordinada aos princípios ecológicos e ao primado de uma vida digna aos seres humanos, procurando evitar que o egoísmo de certas minorias sobreponha-se ao interesse comum de sobrevivência da coletividade global e do Planeta Terra ${ }^{36}$.

É diante dessa percepção que se pretende criar estudos e ensaios com a finalidade de esclarecer a forma racional de desenvolvimento da pessoa e o progresso humano universal. $\mathrm{O}$ meio ambiente passou a ser definido como um direito humano fundamental, pois não há qualidade de vida se não houver a existência ou a possibilidade de existir um meio ambiente ecologicamente equilibrado e sadio, que se traduz no modo fundamental da dignidade humana ${ }^{37}$. Um meio ambiente com qualidade integra o conteúdo normativo da dignidade humana, fato este essencial, pois integra o conceito de manutenção e de existência da vida com qualidade ${ }^{38}$.

Tendo em vista os problemas ecológicos e o enquadramento do desenvolvimento sustentável, há inquietudes a serem pacificadas. Essa degradação ambiental é decorrência, em grande parte, de desigualdades sociais, as quais devem ser solucionadas de forma a buscar, socialmente, as condições mínimas de existência digna.

34 CAPRA, Fritjof. A Teia da vida: uma nova compreensáo científica dos sistemas vivos. Tradução Newton Roberval Eichemberg. 4. ed. São Paulo: Cultrix, 1999, p. 28.

35 LEFF, Enrique. Saber ambiental: sustentabilidade, racionalidade, complexidade, poder. Petrópolis: Vozes, 2012, p. 222.

36 MILARÉ, Édis. Direito do ambiente. São Paulo: Editora Revista dos Tribunais, 2013, p. 57

37 SARLET, Ingo Wolfgang. Direito constitucional ambiental: Constituiçáo, direitos fundamentais e proteçáo do ambiente. São Paulo: Revista dos Tribunais, 2012, p.12.

38 SARLET, Ingo Wolfgang. Direito constitucional ambiental: Constituição, direitos fundamentais e proteçáo do ambiente. São Paulo: Revista dos Tribunais, 2012, p.13. 
Nesse quadro, há uma estrada para as novas tecnologias, para as inovaçôes regularem a pacificaçáo desse problema ambiental. $\mathrm{O}$ crescimento econômico e social acelera a degradação ambiental, pelo fato de que crescimento não está para o desenvolvimento, sendo que aquele se utiliza dos meios naturais para sua concretude. Nessa perspectiva do uso intolerável dos recursos, diante do crescimento acelerado, nasce à preocupação em protegê-los e preservá-los para que a vida terrena tenha continuidade própria.

$\mathrm{O}$ contexto social enquadra-se em um argumento individualista, de consumo exagerado, o meio social clama pelas iniciativas decorrentes das novas tecnologias. Nessa linha de pensamento, a intenção de recorrer a recursos tecnológicos para socorrer os dados alarmantes quanto à preservação dos meios naturais deve fazer parte da conscientização das pessoas que detém o poder, seja ele econômico ou científico. Isso pode se revelar positivo na direção de preservar os meios naturais essenciais para a vida no planeta e para restaurar, reconstruírem-se aqueles que se encontram escassos.

Contudo, enquanto os grupos econômicos, ou seja, a sociedade com poder, náo aderirem à forma de pensar de que o crescimento não deve estar correlacionado com a degradaçáo do meio natural, nem mesmo as formas primárias de tecnologia amenizarão a situação crítica em que se encontra o meio natural.

A ciência e a tecnologia são duas ferramentas que, conjuntamente, formam um elo infalível, um meio eficaz para as expectativas de superação da crise ambiental. As açôes humanas estão, cada vez mais, relacionadas ao meio natural devendo a ciência jurídica, por meio de suas bases principiológicas, precaverem danos que possam comprometer a continuidade da vida humana.

Compartilha-se da ideia de Jacques Marcovitch, o qual afirma que, contemporaneamente, a tecnologia é um instrumento necessário para salvar o Planeta dos riscos que ela mesma teria criado, pois, as inovaçôes ocorridas nos últimos anos demonstraram que a ciência e a tecnologia podem ser utilizadas de forma errada. Os estragos causados ao meio ambiente podem ser sanados pelo uso das novas tecnologias, mesmo sabendo-se que a maioria desses danos foram causados por ela mesma. Contudo, hoje, se aplicados para o fim de recuperar a esfera natural, poderão surtir resultados benéficos ${ }^{39}$.

Sobre o contraponto entre a forma de crescimento e desenvolvimento, aduz Henrique Rattner que "o crescimento econômico não é condição suficiente para o desenvolvimento sustentável, que deve ser concebido como um processo de melhora da condiçáo humana, ao longo do tempo, por um crescimento da autoestima e da dignidade da existência ${ }^{40 "}$. A forma do sistema capitalista, o qual visa ao acúmulo de riqueza a "qualquer preço”, em poder de uma sociedade mínima, torna a convivência humana insustentável.

39 MARCOVITCH, Jacques. Para mudar o futuro. Mudanças climáticas, políticas públicas e estratégias empresariais. São Paulo: Saraiva 2006, p. 102

40 RATTNER, Henrique. Uma ponte para a sociedade sustentável. São Paulo: SENAC, 2012, p. 310. 
Com o espaço da modernização, fruto do progresso industrial, vivencia-se um novo quadro social, uma sociedade de risco. Nessa era capitalista, a forma de desenvolver-se está voltada para o alto consumo e para produção, aumentando os riscos sociais, multiplicados pelos processos da modernização. Essa conjunta dos riscos em que a sociedade cria, vive e teme, decorre de açóes e de efeitos que podem perdurar por muito tempo. E, durante este tempo, o grupo social padece, cada vez mais, de medo de que os efeitos de natureza prejudiciais sejam por ele sofridos, vivendo, diariamente, uma angústia e incerteza ${ }^{41}$.

A sociedade civil moderna, diante do comportamento irracional, o qual desfruta da degradação ambiental como meio ou caminho das relaçóes sociais, coloca em risco o bem-estar social de forma individual e coletiva. Como forma de exemplificar a forma na qual há preocupaçôes em minimizar a produção e o consumo exacerbado, Jeremy Rifkin ${ }^{42}$ o exemplo da empresa Nike:

Quizás uno de los mejores ejemplos de cómo funcionan las nuevas fuerzas y tendencias comerciales sea el de la empresa Nike. Nike es, en todos los aspectos y en todos sus objetivos, una empresa virtual. Mientras que los consumidores es probable que piensen en esta empresa como en un fabricante industrial de calzado deportivo, de hecho la empresa es un estudio de investigación y diseño con una fórmula de marketing y de distribución sumamente elaborada. A pesar de ser la primera empresa mundial fabricante de calzado deportivo, Nike no posee ninguna fábrica, ni máquinas, ni equipamientos, ni bienes inmobiliarios por así decirlo. Por el contrario, ha establecido una amplia red de proveedores - a los que llama «socios de producción» en el sudeste asiático, que son quienes le producen sus centenares de diseños de zapatos, ropa y complementos. Nike también externaliza buena parte de sus campañas de publicidad y las diversas operaciones de comercialización. De hecho, el éxito de la empresa durante los años noventa se puede atribuir en buena medida a las innovadoras campańas publicitarias realizadas por Weiden and Kennedy, que fue la empresa de publicidad que ayudó a convertir a Nike en el calzado deportivo más codiciado del mundo”.

No contexto social, para a busca do desenvolvimento sustentável, a ciência tecnológica acaba por respaldar uma importante e valiosa função, a de desenvolver equipamentos propulsores da atividade econômica que causem uma menor degradação do meio

41 SPENGLER, Adriana Maria Gomes de Souza. Flexibilização da soberania dos estados em matéria penal na sociedade global de riscos - A possibilidade de um direito penal transnacional. MONTE, Mario Ferreira. Direitos humanos e sua efetivação na era da transnacionalidade: debate luso-brasileiro. Curitiba: Juruá, 2012, p. 103

42 RIFKIN, Jeremy. La Era del Acceso. La revolución de la nueva economia. Traducción: J. Francisco Álvarez y David Teira. Barcelona: Paidós, 2013, p. 74. 
ambiente e que seja menos maléfica à saúde humana. Como se sabe, a atividade humana está diretamente relacionada ao meio natural; são fatos inseparáveis ${ }^{43}$

Contudo, enquanto os grupos econômicos, ou seja, a sociedade com poder, não aderirem à forma de pensar de que o crescimento não deve estar correlacionado com a degradação do meio natural, nem mesmo as formas primárias de tecnologia amenizarão a situação crítica em que se encontra o meio natural.

Essa percepção encontra nas novas tecnologias um caminho aberto para efetivar os preceitos da sustentabilidade. A descoberta por novas ciências tecnocientíficas instaura-se na agenda de discussão mundial, voltada para a preservação da vida. "Não há como negar que a ciência nos levou a um novo cenário nos quais sonhos e, também pesadelos podem ser realidade".

A ciência tem um poder de modificar o percurso normal e limitado da vida humana, condicionando o homem à estabilização de seus desejos, requerendo a predeterminação da vida, auto-instrumentalizado a espécie humana, como razão para distanciar acontecimentos naturais trágicos ${ }^{45}$.

As ciências biotecnológicas precedem o poder do conhecimento científico que, naturalmente, influencia a humanidade. As novas ciências demandam gastos econômicos, realidade presenciada por países desenvolvidos, os quais concentram o poder econômico no poder do conhecimento, não expandindo o progresso científico às demais comunidades estatais. Uma racionalidade de desenvolvimento insustentável, de progresso em decrescimento, pois a preocupação é a proteção da vida humana não sendo uma barreira pretensa que imporia os benefícios humanitários das novas tecnologias.

Henrique Rattner aponta que "a inovaçóes tecnológicas devem assegurar a equidade e a justiça social e econômica nas sociedades contemporâneas e entre essas sociedades, pode-se considerar as inovaçóes uma condição necessária para a continuidade ou a sustentabilidade do processo de desenvolvimento ${ }^{46 "}$. Considera-se isso como condição necessária ao processo de desenvolvimento, diante da realidade social, a qual desprende uma concepção de que todo ato de crescimento dependa da agressão ao meio natural. Essa forma de atuar e pensar devem ser banidos, pois há outros meios, outras formas de prosperar sem degradar os meios naturais.

43 EFING, Antonio Carlos. Direito e questóes tecnológicas: aplicados no desenvolvimento social. Antônio Carlos Efing e Cinthia Obladen de Almendra Freitas (Orgs.). Curitiba: Juruá, 2012, p. 192.

44 BRAUNER, Maria Claudia Crespo. Biotecnologia e produção do Direito: consideraçóes acerca das dimensōes normativas das pesquisas genéticas no Brasil. SARLET, Ingo Wolfgang (org.). Direitos fundamentais e biotecnologia. São Paulo: método, 2008, p. 177.

45 HABERMAS, J. O futuro da natureza humana. Sáo Paulo: Martins Fontes 2004, p. 20.

46 RATTNER, Henrique. Uma ponte para a sociedade sustentável. São Paulo: SENAC, 2012, p. 373. 
Países desenvolvidos, com vasto crescimento econômico, com uma visão de reconstrução dos recursos naturais não renováveis repousam no crescimento de novos conhecimentos científicos. O ser humano está preocupado com a economia, com o acúmulo de poder, o que contrapóe os fundamentos das inovações tecnológicas.

Para desencadear um desenvolvimento sustentável, a ciência e a tecnologia terão que estar na mesma linha de raciocínio. Os recursos naturais, essenciais para a vida humana, são finitos e sua escassez ou seu término causam insegurança para o ser humano quanto à sua qualidade de vida. Os avanços tecnológicos devem propiciar meios para amenizar os riscos ambientais, promovendo-se a sustentabilidade, a qual visa à disponibilidade de recursos naturais indispensáveis para a sobrevivência humana das presentes e futuras geraçóes.

A ciência da biotecnologia deslocará o conhecimento para o espaço existente entre o homem e o meio ambiente. Nessa esfera de conhecimento, tem-se a ideia de estimular o conhecimento decorrente do saber científico, na intenção de se encontrar um caminho seguro e eficaz para a solução de impasses, desafios da pós-modernidade com o domínio do poder biotecnológico.

A ciência, com seus avanços e conquistas, deve atender à população em geral, pois se está diante da efetivação de um direito universal, a saúde humana e o bem-estar social. A pesquisa científica deve trilhar um caminho no qual não haja a exploração científica que coloque em risco a vida humana ou, ainda mais em perigo, se a ciência, por meio de suas descobertas, centralize nas mãos de poucos os efeitos científicos, com a finalidade de promover o mercado científico.

Com base nos ensaios de Ingo Wolfgang Sarlet, o princípio norteador da espécie humana está na dignificação do ser, pois a liberdade, a igualdade, o bem-estar, a segurança e até mesmo a forma de desenvolvimento sustentável, descendem, originam-se do primado maior que é o respeito à dignidade do ser humano. Esses conjuntos de direitos, caracterizados como fundamentais, devem nortear as novas etapas sociais no caminho da dignificação pessoal. No que diz respeito às novas tecnologias, para que seja aceita sua inserção no meio social, devem ter como fundamento a dignidade da pessoa humana ${ }^{47}$. "O avanço tecnológico deverá buscar não apenas a manutenção da vida ou o seu prolongamento, analisando sob o prisma quantitativo, mas deverá perseguir a mantença ou prolongamento com qualidade, ou seja, com dignidade ${ }^{48 ”}$.

47 SARLET, Ingo Wolfgang; FENSTERSEIFER, Tiago. Direito constitucional ambiental: Constituiçáo, direitos fundamentais e proteçáo do ambiente. São Paulo: Editora Revista dos Tribunais, 2012, p. 50 .

48 SARLET, Ingo Wolfgang; FENSTERSEIFER, Tiago. Direito constitucional ambiental: Constituição, direitos fundamentais e proteçáo do ambiente. São Paulo: Editora Revista dos Tribunais, 2012, p. 50 . 
A ciência, bem como seu avanço por meio das tecnologias, da própria biotecnologia, ascende uma esperança para com a crise ambiental que se instaura na maioria dos países, sejam eles desenvolvidos ou em fase de desenvolvimento. A inserção da forma de desenvolvimento sustentável é um meio para que a sociedade civil passe a pensar e a agir de forma diversa, em prol da preservaçáo do entorno natural. Que suas atitudes desenvolvimentistas não recaiam na base ecológica como forma de devastação e degradação, mas, sim, que haja uma sintonia entre o ato de progresso e a preservação do meio ambiente.

A ciência tecnológica, quando voltada para a salvaguarda dos direitos humanos fundamentais, tal como, ao meio ambiente sadio e ecologicamente equilibrado, conduz o paradigma da sustentabilidade de forma concreta ao meio social. Com isso, está-se diante de meio que poderá transformar ou recriar energias renováveis, limpas, sem degradar o meio ambiente. Com a contribuição da ciência e da tecnologia, pode-se pensar em uma nova forma de civilização, fundamentada no uso racional dos recursos renováveis.

\section{Conclusões}

Diante das devastações ambientais, tragédias climáticas, desmatamentos florestais, poluição da água, do solo e do ar, entre tantas outras catástrofes ambientais, a cada dia colocam em risco a sobrevivência da sociedade e demais seres vivos.

O não pensar no hoje, para garantir uma sobrevivência digna no futuro, enfatiza uma irracionalidade social, uma forma de operar irracional, insustentável. A sustentabilidade como um princípio para garantir a continuidade da vida terrena, ou um desenvolvimento sustentável com o pensamento nas açóes presentes e futuras, sem prejuízo de vida quanto aos recursos naturais, é uma forma de resguardar, de preservar um direito fundamental, o bem natural como fonte de subsistência. A comunidade atual não deve apenas pensar em sustentar recursos disponíveis, mas, de forma satisfatória, propiciar condiçóes melhores às geraçôes futuras. $\mathrm{O}$ agir momentâneo com reflexos futuros.

A base dimensional da sustentabilidade tende a ser estruturada por meio do social, da economia e do ambiental, não sendo possível a inserção dos efeitos tecnológicos como base da estrutura primária, mas, sim, como respostas aos seus efeitos no contexto social. Nessa ideologia, está no conhecimento da ciência a esperança de utilizar-se dos recursos naturais dispostos pelo capital natural, sem sua degradação ou extinção. O sistema da biodiversidade vai ao encontro dos parâmetros da biotecnologia para haver uma forma harmônica de desenvolvimento social e preservação ecológica.

Nessa seara que nasce a inquietaçáo de questionar quais são as responsabilidades e os limites que se devem impor para resguardar o respeito aos direitos humanos, o respeito e a preservação do meio ambiente. Esse equilíbrio entre a ciência, a vida e o meio ambiente devem conduzir a uma forma sustentável de progresso. Um meio ambiente ecologicamente 
equilibrado significa preservar a base biológica natural, estando à sociedade à mercê dos interesses de novas ciências, com a preservação e a utilização racional dos recursos naturais. E, para que haja a efetiva preservação, o Poder Público deverá ser atuante quanto à fiscalização das entidades compromissadas com o desenvolvimento do conhecimento científico.

Essa percepção encontra nas novas tecnologias um caminho aberto para efetivar os preceitos da sustentabilidade. A descoberta por novas ciências tecnocientíficas instaura-se na agenda de discussáo mundial, voltada para a preservação da vida. A ciência tem um poder de modificar o percurso normal e limitado da vida humana, condicionando o homem à estabilização de seus desejos, requerendo a predeterminação da vida, auto-instrumentalizando a espécie humana, como razão para distanciar acontecimentos naturais trágicos.

As ciências biotecnológicas precedem o poder do conhecimento científico que, naturalmente, influencia a humanidade. As novas ciências demandam gastos econômicos, realidade presenciada por países desenvolvidos, os quais concentram o poder econômico no poder do conhecimento, não expandindo o progresso científico às demais comunidades estatais. Uma racionalidade de desenvolvimento insustentável, de progresso em decrescimento, pois a preocupação é a proteção da vida humana não sendo uma barreira pretensa que imporia os benefícios humanitários das novas tecnologias.

Nesse contexto, aumenta a preocupação com os recursos naturais, no sentido de que o desenvolvimento econômico prescinde o desenvolvimento científico, que, na sua função, promove o desenvolvimento social, o bem-estar social. Não deve haver limitação ou restrição do direito à vida.

Esse equilíbrio entre a ciência, a vida e o meio ambiente devem conduzir a uma forma sustentável de progresso. Um meio ambiente ecologicamente equilibrado significa preservar a base biológica natural, estando a sociedade à mercê dos interesses de novas ciências, com a preservação e a utilizaçáo racional dos recursos naturais.

O desenvolvimento sustentável vai além de uma harmonia entre os aspectos econômicos e ambientais e enfatiza uma nova ordem de valores morais, no que tange à preservação de meios indispensáveis, para a existência humana presente, sem comprometer a vida das futuras geraçóes. Nessa linha de preservar o hoje para existir no amanhá, ressalta-se a importância da evolução científica, das novas tecnologias para resguardar e preservar os recursos naturais indispensáveis para a existência humana. Não estando inserido tão somente no aspecto do crescimento econômico como também do conhecimento científico, deve-se voltar para os aspectos sociais deficitários, buscando, por meio do princípio solidário, a equalização dos direitos que garantem o mínimo existencial.

A era ambiental tende a reabrir o conflito entre a exploração e a libertação humana numa nova forma de pensar. Com a libertação do ser humano para a produção, sem 
atentar para a escassez de recursos, tendenciou o açodamento do alarme na esfera ecológica, sendo a área atingida, de forma primária e emergencial, como as etapas ocultas do progresso e da modernização mundial. Nessa realidade, que há necessidade de haver uma conscientização ambiental, uma mudança de valores pós-modernos em face da degradação ambiental. Por meio da maximização da economia, poderia haver os reflexos da sustentabilidade, com o melhor uso dos recursos em prol do meio ambiente e do seu crescimento econômico futuro. Uma construção social que visa ao desenvolvimento da pessoa humana de forma linear com o meio ambiente, perfazendo-se, uma construçáo do desenvolvimento sustentável.

\section{Referências}

AUMOND, Juarêz. As perspectives do desenvolvimento sustentável. IN BENEVIDES, Mario e VALDEZ, Silvia (org.). Nós e a sustentabilidade. Florianópolis: Relata, 2012.

BARBOSA, Gisele Silva. O desafio do desenvolvimento sustentável. Revista Visóes. 4a. ed, n. 4, Vol. 1 - Jan/Jun, 2008. Disponível em: http://www.fsma.edu.br/visoes/ ed04/4ed_O_Desafio_Do_Desenvolvimento_Sustentavel_Gisele.pdf. Acessado em 15 de março de 2015.

BRAUNER, Maria Claudia Crespo. Biotecnologia e produção do Direito: considerações acerca das dimensôes normativas das pesquisas genéticas no Brasil. SARLET, Ingo Wolfgang (org.). Direitos fundamentais e biotecnologia. São Paulo: método, 2008.

BRASIL, Constituição Federal do Brasil de 1988. Disponível em: http://www.planalto. gov.br/ccivil_03/constituicao/constitui\%C3\%A7ao.htm. Acessado em 19 de agosto de 2012.

CAPRA, Fritjof. A Teia da vida: uma nova compreensão científica dos sistemas vivos. Tradução Newton Roberval Eichemberg. 4. ed. São Paulo: Cultrix, 1999.

COELHO, Saulo de Oliveira Pinto; ARAÚJO, André Fabiano Guimarães de. A sustentabilidade como princípio constitucional sistêmico e sua relevância na efetivaçáo interdisciplinar da ordem constitucional econômica e social: para além do ambientalismo e do desenvolvimentismo. Revista da Faculdade de Direito de Uberlândia, v. 39:261-291, de 2011.

DIAS, Bruno Smolarek; MARDEGAN, Herick. Sustentabilidade como fundamento da cidadania transnacional. Revista Eletrônica Direito e Política, Programa de Pósgraduação Stricto Sensu em Ciência Jurídica da UNIVALI, Itajaí, V.6, n.2, 20 quadrimestre de 2011. Disponível em: WWW.univali.br/direitopolitica - ISSN 19807791. 
EFING, Antonio Carlos. Direito e questóes tecnológicas: aplicados no desenvolvimento social. Antônio Carlos Efing e Cinthia Obladen de Almendra Freitas (Orgs.). Curitiba: Juruá, 2012.

FREITAS, Juarez. Sustentabilidade: direito ao futuro. Belo Horizonte: Fórum, 2012.

FERRER, Gabriel Real. Calidad de vida, médio ambiente, sostenibilidad y ciudadanía. Construímos juntos el futuro? Revista NEJ - Eletrônica, Vol. 17 - n. 3 - p. 319 / set-dez 2012 321. Disponível em: www.univali.br/periodicos. Acesso em 19 de março de 2015.

HABERMAS, J. O futuro da natureza humana. São Paulo: Martins Fontes. 2004.

JUNGES, José Roque. Ética ambiental. São Leopoldo: Unisinos, 2004.

LEFF, Enrique. Saber ambiental: sustentabilidade, racionalidade, complexidade, poder. Petrópolis: Vozes, 2012.

MARIANO, Leila. O poder judiciário e a sustentabilidade. In: FLORES, Nilton César (Org.). A sustentabilidade ambiental e suas múltiplas faces. Campinas: Millennium, 2012.

MARCOVITCH, Jacques. Para mudar o futuro. Mudanças climáticas, políticas públicas e estratégias empresariais. São Paulo: Saraiva 2006.

MILARÉ, Édis. Direito do ambiente. São Paulo: Editora Revista dos Tribunais, 2013.

NEVES, Lafaiete Santos (org). Sustentabilidade. Anais de textos selecionados do V seminário sobre Sustentabilidade. Curitiba: Juruá, 2011.

Nosso Futuro Comum. Disponível em: http://pt.scribd.com/doc/12906958/ RelatorioBrundtland-Nosso-Futuro-Comum-Em-Portugues. Acessado em 15 de agosto de 2012.

RATTNER, Henrique. Uma ponte para a sociedade sustentável. São Paulo: SENAC, 2012.

RIFKIN, Jeremy. La Era del Acceso. La revolución de la nueva economia. Traducción: J. Francisco Álvarez y David Teira. Barcelona: Paidós, 2013.

SARLET, Ingo Wolfgang; FENSTERSEIFER, Tiago. Direito constitucional ambiental: Constituição, direitos fundamentais e proteçáo do ambiente. São Paulo: Editora Revista dos Tribunais, 2012.

SARLET, Indo Wolfgang; FENSTERSEIFER, Tiago. Estado socioambiental e mínimo existencial (ecológico): algumas aproximaçóes. SARLET, Ingo Wolfgang. Estado socioambiental e direitos fundamentais. Porto Alegre: Livraria do Advogado, 2010.

SARLET, Ingo Wolfgang. Direito constitucional ambiental: Constituição, direitos fundamentais e proteçáo do ambiente. São Paulo: Revista dos Tribunais, 2012. 
SPENGLER, Adriana Maria Gomes de Souza. Flexibilização da soberania dos estados em matéria penal na sociedade global de riscos - A possibilidade de um direito penal transnacional. MONTE, Mario Ferreira. Direitos humanos e sua efetivaçáo na era da transnacionalidade: debate luso-brasileiro. Curitiba: Juruá, 2012.

SOUZA, Maria Cláudia Silva Antunes de; MAFRA, Juliete Ruana. A sustentabilidade no alumiar de Gabriel Real Ferrer: reflexos dimensionais na Avaliação Ambiental Estratégica In: SOUZA, Maria Claudia Silva Antunes; GARCIA, Heloise Siqueira Org(s). Lineamentos sobre sustentabilidade segundo Gabriel Real Ferrer. Itajaí: UNIVALI, 2014.

SOUZA, Maria Cláudia S. Antunes de; MAFRA, Juliete R. .A Sustentabilidade e o ciclo do bem estar: o equilíbrio dimensional e a ferramenta da avaliaçáo ambiental estratégica. Nomos (Fortaleza), v. 34, 2014.

VEIGA, José Eli da. Sustentabilidade: a legitimação de um novo valor. São Paulo: Editora SENAC, 2012. 